\title{
Minimal Chewing or Mashing with Majority of Bolus Unchewed
}

National Cancer Institute

\section{Source}

National Cancer Institute. Minimal Chewing or Mashing with Majority of Bolus Unchewed. NCI Thesaurus. Code C127201.

A finding of minimal chewing or mashing with majority of bolus unchewed prior to swallowing. 